\section{ATMOSPHERIC TIDES.}

$A \mathrm{~N}$ article on atmospheric tides, by $\mathrm{Mr}$. W. Krebs, who is a frequent contributor to the scientific literature of Germany, appears in Das Weltall, a Berlin journal of astronomy, of December, 1903. The author points out that the astronomer Mädler demonstrated in 1837 from the Berlin barometer observations the existence of an oscillation of air pressure in the course of a lunar day. The mean range exhibited a minimum pressure in the afternoon and a maximum in the forenoon of that period. This occurrence, which was found by. Mädler for the years $1820-1835$, was confirmed by Prof. Börnstein with reference to the years $1884-1888$, and was also shown to obtain at other German stations. But neither of these physicists ventured to affirm the existence of a tidal movement of the atmosphere in the oscillation which they had discovered.

The hitherto purely statical conception of the oscillations of air-pressure was an obstacle to such a theory. This conception supposed a maximum of pressure to be simply the result of an elevation, and a minimum to be the result of a depression of the barometric column. According to this still prevalent idea, a maximum of pressure must be expected at the time of the upper culmination, and a minimum at the time of the lower culmination of the moon. The former was, however, found to occur at Berlin almost exactly five lunar hours after the upper culmination, and the latter about the same time after the lower culmination. For these reasons Mädler thought it possible "that there was a third way in which the celestial bodies acted upon each other, which was still unknown to us," that is to say, other than by radiation and gravitation.

But the atmospheric oscillation in the course of a lunar day, first discovered by Mädler, appears to be nothing more than a wave caused by gravitation, when it is considered as a transverse oscillation and explained dynamically. The greatest rarefaction of the air occurs about half-way after the lower culmination, corresponding to the greatest uprising movement of the medium. The greatest compression of the air occurs about half-way after the upper culmination, corresponding to the greatest downward movement of the medium. In both cases an attraction of the moon on the lower atmosphere of the earth is presupposed. The third kind of mutual action between the celestial bodies assumed by Mädler accordingly reveals itself, in the case in question, as simply gravitation, when its effect is only considered from the standpoint of the wave theory. When applied to the solar day, the author considers that this view of the matter completes a missing link in the explanation of the double atmospheric oscillation according to Kelvin and Hann.

\section{ON LEAD POISONING AND WATER SUPPLIES.}

THE second volume on the above subject has recently been issued by the medical officer of the Local Government Board. The former volume contained information roncerning Dr. Houston's study of waters derived from moorland gathering grounds in Lancashire and Yorkshire the present volume gives details of an extensive series of laboratory experiments bearing on the general subject and conducted by Dr. Houston. They have been published in order to facilitate the interpretation of the results obtained when studying the solvent or erosive power of a water on lead pipes, with the view of counteracting these dangerous qualities. Particular attention is directed to observations on "standards" (p. 443) in this volume, where methods of measuring the solvent and erosive powers of a water upon lead are given enabling an opinion to be formed as to the degree of risk arising from the contact of such water with lead surfaces.

The report is illustrated with drawings of the apparatus employed in the investigations, and photographs have been reproduced to show the actual amount of deposit remaining in the tubes in which the erosion of lead by water had been allowed to take place.

From the nature of this report it will be understood that the substance of it consists of the tabulated results, together with brief descriptions of the experimental methods adopted. The main conclusions arrived at were stated in the previous volume, but a general summary of all conclusions is also given in Section iv. of this volume. A reference to this summary will be found useful to those who are concerned with the consideration of dangers of lead poisoning arising from water supplies.

The summary starts with an explanation of the meaning of the term "erosion," and proceeds to state that bright lead is rapidly eroded by rain and by snow water, as well as by distilled water; then follow the names of substances which do not influence the erosive power of water when introduced into it, as well as of substances which delay and inhibit the action. Moorland waters are next considered in regard to their erosive property, and the conditions which increase, diminish, or prevent their erosion are stated. Then follow waters which do not fall under the above classification, together with remedial measures which may be adopted to avoid danger. A similar classification and consideration of waters as regards plumbo-solvency is then shortly entered into, and, finally, the conclusions arrived at from chemical and bacteriological experiments as to the cause of acidity in moorland water are given. The summary terminates with a selection of conclusions which have already appeared in the former volume.

F. C.

\section{UNIVERSITY AND EDUCATIONAL \\ INTELLIGENCE.}

DR. H. H. Dixon has been elected professor of botany at Trinity College, Dublin, in succession to Dr. E. Percival Wright, who has resigned.

The Princess of Wales opened the new buildings of the St. Paul's Girls' School at Brook Green, London, W:, on April 15. Accommodation is provided for a museum, chemical laboratory, and practical physics.

At the request of the Board of Treasury the following gentlemen have consented to act as a committee to consider the allocation of the proposed increased grant to the university colleges giving education of a university standard in arts and science, viz. the Right Hon. R. B. Haldane, M.P. (chairman), Sir F. Mowatt, G.C.B., I.S.O., Mr. C. A Cripps, K.C., M.P., the Rev. Dr. Woods, late president of Trinity College, Oxford. Mr. Henry Higgs, of the Treasury, will act as secretary.

AN annual commemoration day was inaugurated at the University of Glasgow on Tuesday. Sir William Ramsay gave a discourse on Joseph Black's life and scientific work, and after the oration several honorary degrees were conferred. At the commemoration banquet on Tuesday evening Mr. Choate, the United States Ambassador, remarked in the course of a speech that the universities had to do their best for the guidance of the councils of the nations to which they belonged.

THE council for the extension of higher education in North Staffordshire has issued its report for 1903. I he objects of the council are to stimulate interest in higher education throughout the district, to assist in coordinating institutions and classes for higher and technical instruction, to aid existing institutions by the provision of supplementary and advanced courses of instruction, and to take steps for the establishment of a suitable institution in which to conduct a scheme of higher education for the benefit of the whole district. The report gives, among other information, reasons for the establishment as soon as possible of the proposed North Staffordshire University College, and urges the members of the council to join in the promotion of the scheme.

Trie United States consul at Leipzig has, says Science, compiled a table of the number of students attending twenty-one German universities during the winter 1903-4. The total number of matriculated students at these universities is 37,854 , of whom 3093 are foreigners, the largest number ever recorded. The number of foreign students is equivalent to 8.2 per cent. of the total number. Of other students attending lectures in these universities there are 7874 men and $13 \mathrm{I} 3$ women, so that the total number of students is $47,04 \mathrm{I}$. Noteworthy among other things in the 